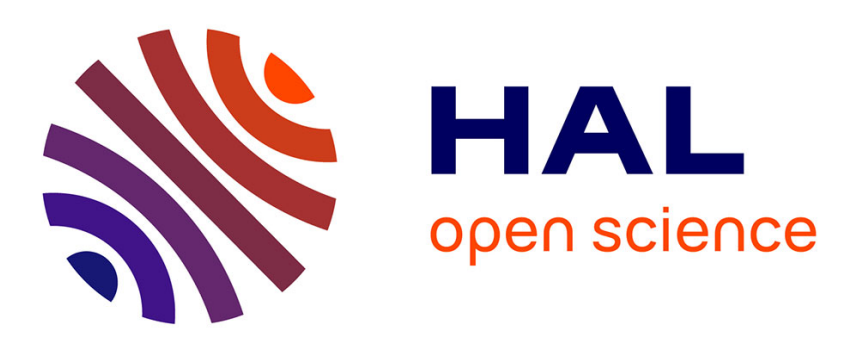

\title{
Linking the transpirable soil water content of a vineyard to predawn leaf water potential measurements
}

\author{
Rémi Gaudin, S. Roux, B. Tisseyre
}

\section{To cite this version:}

Rémi Gaudin, S. Roux, B. Tisseyre. Linking the transpirable soil water content of a vineyard to predawn leaf water potential measurements. Agricultural Water Management, 2017, 182, pp.13-23. 10.1016/j.agwat.2016.12.006 . hal-01581423

\section{HAL Id: hal-01581423 \\ https://hal.science/hal-01581423}

Submitted on 4 Sep 2017

HAL is a multi-disciplinary open access archive for the deposit and dissemination of scientific research documents, whether they are published or not. The documents may come from teaching and research institutions in France or abroad, or from public or private research centers.
L'archive ouverte pluridisciplinaire HAL, est destinée au dépôt et à la diffusion de documents scientifiques de niveau recherche, publiés ou non, émanant des établissements d'enseignement et de recherche français ou étrangers, des laboratoires publics ou privés. 
Linking the transpirable soil water content of a vineyard to predawn leaf water potential measurements

Rémi Gaudin*a, Sébastien Roux ${ }^{\mathrm{b}}$, Bruno Tisseyre $^{\mathrm{c}}$

${ }^{a}$ Montpellier SupAgro, UMR SYSTEM (INRA-CIRAD-SupAgro), 2 place Viala, 34060 Montpellier Cedex 2, France.

' INRA, UMR SYSTEM (INRA-CIRAD-SupAgro), 2 place Viala, 34060 Montpellier Cedex 2, France.

${ }^{c}$ Montpellier SupAgro, UMR ITAP (IRSTEA-SupAgro), 2 place Viala, 34060 Montpellier Cedex 2, France.

* Corresponding author Tel.: +33 49961 2059; fax: +33 499613034

E-mail address: remi.gaudin@supagro.fr

\section{ABSTRACT}

A new expression of the time derivative of predawn leaf water potential was proposed by equalizing two expressions of the grapevine transpiration. This expression was established when transpiration is the only driver of the vineyard water balance. Under Mediterranean climate, this condition is met for long periods of drought i.e. most of the summer time under the hypothesis that there is no water movement (capillary rise) from the deep layers of the soil. The proposed approach showed that changes in predawn leaf water potential $\left(\Psi_{\mathrm{pd}}\right)$ values are in inverse relation with the Total Transpirable Soil Water (TTSW) which characterizes the maximal water stock of the soil and in direct relation with reference evapotranspiration $\left(\mathrm{ET}_{\mathrm{o}}\right)$ and the basal crop coefficient $\left(\mathrm{k}_{\mathrm{cb}}\right)$ of the vine. The relation between $\Psi_{\mathrm{pd}}$ changes and cumulated $\mathrm{ET}_{\mathrm{o}}$ is linear with a slope related to the ratio of " $k_{\mathrm{cb}}$ to TTSW". This ratio can be therefore estimated from field measurements and climatic data.

This approach was tested on two year observations performed by Acevedo-Opazo et al. (2010) in vineyards cultivated with cv. Shiraz and Mourvedre, without any irrigation. Analysis of the data obtained in 49 sites per vineyard for several dates in the very dry summers of 2003 (Shiraz) and 2005 (Mourvedre) showed strong and significant adjustments of the model. These results proved the linear relationship between the sum of $\mathrm{ET}_{\mathrm{o}}$ and $\Psi_{\mathrm{pd}}$. For each site of the vineyard, the approach demonstrated the possibility to provide site-specific estimates of the ratio of $\mathrm{k}_{\mathrm{cb}}$ to TTSW. This theoretical and practical development could have applications for water management and soil studies in Mediterranean vineyards.

Keywords: Vitis vinifera L., soil water balance, Mediterranean vineyard, water stress 


\section{Introduction}

Many studies have shown that the dynamic of the grapevine water status determines the grape yield as well as grape quality at harvest (van Leeuwen et al., 2004; Deloire et al., 2005; Pellegrino et al., 2006; Gaudin et al., 2014b). When soil water content measurements are possible, the grapevine water status can be defined by the fraction of transpirable soil water (FTSW) (Lebon et al., 2003; van Leeuwen et al., 2009). The $F T S W$ has to remain high during the vegetative growth in order to avoid significant water restrictions. After flowering, it should decrease and generate moderate water stress to give priority to generative over vegetative development (Pellegrino et al., 2004, 2005).

In Mediterranean conditions where significant water restrictions are regularly observed, the vine water status is commonly estimated through the pre-dawn leaf water potential ( $\left.\Psi_{p d}\right)$ (Ojeda et al., 2001; Pellegrino et al., 2004; Ojeda, 2007). Environmental and varietal factors influence $\Psi_{p d}$ in the field. Among environmental factors, the soil type (Koundouras et al., 2006) and the depth of the water-table at the landscape scale (GuixHebrard et al., 2007) are considered as the most important. Varietal effects on $\Psi_{p d}$ values were clearly identified by Schultz (2003) and Ojeda et al. (2005). However, it seems that this only explains differences in $\Psi_{p d}$ values for moderate water restrictions while the soil factor explains differences in $\Psi_{p d}$ values for high level of water restrictions (Taylor et al., 2010).

The factors which influence the seasonal dynamic of $\Psi_{p d}$ are also important drivers of the vineyard water balance. Irrigation and rain events rapidly affect the evolution of $\Psi_{p d}$. In Mediterranean vineyards where summer drought occurrence has high probability, it is possible to define an optimum time-course of $\Psi_{p d}$ for the purpose of irrigation management (Ojeda, 2007). It is noteworthy that under dry conditions, the water balance equation is simplified: the evaporation term could be dropped and the soil water loss is assumed to be mainly due to vineyard transpiration in absence of capillary rise. In this condition, change in $\Psi_{p d}$ can reasonably be linked to soil and grapevine variables.

This question is not solely theoretical since long summer drought episodes have already occurred in the twenty-first century, notably in 2003 where $\Psi_{p d}$ values as low as $-1 \mathrm{MPa}$ have been observed by Acevedo-Opazo et al. (2010) putting the vines in extreme water stress conditions. Moreover, a comprehensive view of the $\Psi_{p d}$ dynamic could help optimize the vineyard management during dry conditions. To understand this dynamic of $\Psi_{p d}$ under dry conditions, FTSW has to be considered since it is associated to $\Psi_{p d}$ in the water balance approach. A precise method for estimating FTSW is the use of a neutron probe which gives the water content of deep as well as shallow layers of the soil (Trambouze and Voltz, 2001; Pellegrino et al., 2004; Celette et al., 2008; Gaudin et al., 2010). However, presence of rocks constitutes an obstacle to its proper implementation in too many situations (van Leeuwen et al., 2009).

This difficulty concerns most qualitative Mediterranean vineyards with moderate and controlled yield. Although the experimental estimation of FTSW can be problematic in these cases, its modelling using water balance models has proven to be robust and has given rise to many applications. Models have been applied in vineyards either in bare soil conditions (Lebon et al., 2003; Pellegrino et al., 2006) or with intercrop (Celette et al., 2010; Fandino et al., 2012). Hofmann et al. (2014) recently summarized the advantages and drawbacks of water balance models, recalling the historical context of their development. It leads these authors to recommend the intermediate approach of 
Lebon et al. (2003) which separates the evapotranspiration fluxes of grapevines and bare soil.

The same modelling concepts are used in this paper to focus on the transpiration flux under particular conditions. Our approach is based on a mathematical development equalizing two expressions of the vine water consumption when vine transpiration is its only driver (no evaporative term from the bare soil is considered). This formalization leads to a simple expression of the rate of change of the pre-dawn leaf water potential under dry conditions. This study considers periods of drought commonly experienced by Mediterranean vineyards of the Northern hemisphere in July-August. It applies to vineyards without a water-table. The mathematical derivation of this result and its validation using data from experimental vineyards of Pech Rouge (INRA-Gruissan, $43^{\circ} 08^{\prime} 47^{\prime} \mathrm{N}, 03^{\circ} 07^{\prime} 19^{\prime \prime} \mathrm{E}$ ) in particularly dry years are presented hereafter. Moreover, the dataset covers two different years and two cultivars (cv. Shiraz and Mourvedre) presenting differences in their hydric behavior, at least in moderate stress condition (Prieto et al., 2010; Taylor et al., 2010).

The modelling approach developed thereafter is an inverse approach applied when a long period of time under dry condition occurs. Such a condition is regularly met under rain-fed Mediterranean vineyard a few weeks every year.

Inversion is a classical approach in water balance studies. For instance, Campos et al. (2016) has recently used this method to estimate the Total Available Water of various rain-fed and irrigated vineyards by assimilating actual evapotranspiration data in a water balance model. The method we are proposing is based on reference measurements performed on Mediterranean vineyards: predawn leaf water potential, which are robust and quite commonly used by the wine industry to monitor vine water restriction. It opens the way to estimation of the Total Water reservoir of vineyards at local scale when/where other approaches (soil water measurements) are not possible.

\section{Theory}

In this section the expression of the time derivative of $\Psi_{p d}$ is obtained using modelling concepts classically used in vineyard studies. These concepts applied in first instance for Shiraz (Lebon et al., 2003; Pellegrino et al., 2004) and Gewürztraminer (Lebon et al., 2003) have since been used for soil-vine water studies concerning other varieties: Aranel (Celette et al., 2010), Cabernet-Sauvignon (Gaudin et al., 2014a), Grenache (Pellegrino et al., 2006; Gaudin et al., 2014b), Mourvedre (Pellegrino et al., 2006), Riesling (Gruber and Shultz, 2005; Hofmann et al., 2014).

In the model of Lebon et al. (2003), the soil water content is represented by a reservoir characterized by its Total Transpirable Soil Water $(T T S W, \mathrm{~mm})$, the Available Soil Water (ASW, mm) and the Fraction of Transpirable Soil Water $(F T S W=A S W / T T S W)$ remaining at any time during the season (Sinclair and Ludlow, 1986). The TTSW is measured as the water stock difference between the soil water content profile at field capacity and the driest soil water content profile. In dry conditions, the latter generally takes place around harvest and is usually obtained by multi-year experimentation to make sure the soil profile is in its minimal water condition at least once: examples of these profiles can be found in Pellegrino et al. (2004), Celette et al. (2008), Gaudin et al. (2010).

In this study, it is assumed:

a) no capillary rise from any water-table and no influence from deep layers under the root zone of the vine, 
b) the evaporative flux from the soil surface maintained in bare condition is zero,

c) the soil water content is low and has triggered an active stomatal regulation.

The second condition can be verified in summer approximately ten days after any rain event (Allen et al., 1998) for any vineyards with no intercrop. Less than ten days can be sufficient for this condition to be realized in Mediterranean summer.

When these conditions are met, following Lebon et al. (2003), daily vine transpiration ( $\operatorname{Tr}$ in $\mathrm{mm}^{\mathrm{d}} \mathrm{d}^{-1}$ ) can be summarized by two equations (Eq. 1; Eq. 2):

$$
\begin{aligned}
T r= & (F T S W / 0.4) \times k_{c b} \times E T_{o} \\
& T r=-\mathbf{d} A S W / \mathbf{d} t
\end{aligned}
$$

with:

$k_{c b}$ basal crop coefficient of the vine (no unit), associated to vineyard radiation interception efficiency (Riou et al., 1989; Lebon et al., 2003)

$E T_{o}$ reference evapotranspiration $\left(\mathrm{mm} \cdot \mathrm{d}^{-1}\right)$

Eq. 1 states the regulation of vine transpiration by soil water availability occurring below a given threshold value of FTSW. Lebon et al. (2003) showed that, for Shiraz variety, the stomatal conductance decreases below FTSW $=0.4$. When FTSW $>0.4$, no limitation to the potential climatic demand of the vine is observed as established by Schultz (1996) with stomatal conductance measurements in a Mediterranean vineyard. The vine transpiration is then $k_{c b} \times E T_{o}$. When $F T S W<0.4$, there is a limiting influence of stomatal aperture on both the $\mathrm{CO}_{2}$ assimilation (Pellegrino et al., 2006) and the $\mathrm{H}_{2} \mathrm{O}$ transpiration (Lebon et al., 2003; Hofmann et al., 2014) leading to Eq. 1. This condition is experienced by vines grown without irrigation during most summers in Mediterranean conditions.

Eq. 2 corresponds to the simplified water balance under dry conditions: No rain, no irrigation, no evaporation and no capillary rise.

Equalizing Eq. 1 and Eq. 2 leads to:

$$
\text { - d } A S W / \mathbf{d} t=(F T S W / 0.4) \times k_{c b} \times E T_{o}
$$

Considering the definition of FTSW, it can be stated that:

$$
(\mathbf{d} F T S W) / F T S W=-(1 / 0.4) \times k_{c b} \times E T_{o} \times(1 / T T S W) \times \mathbf{d} t
$$

This last relationship can also be written as:

$$
\mathbf{d}(\operatorname{Ln} F T S W)=-2.5 \times k_{c b} \times\left(E T_{o} / T T S W\right) \times \mathbf{d} t
$$

Lebon et al. (2003) found a relationship between FTSW and $\Psi_{p d}$ recalled in Eq. 4 that appeared stable over different pedo-climatic conditions and cultivars (Pellegrino et al., 2004):

$$
F T S W=1.02 \exp \left\{5.66 \mathrm{x} \Psi_{p d}\right\}
$$

with $\Psi_{p d}$ expressed in MPa. 
From Eq. 4 and Eq. 3, the following relationship between changes in predawn leaf water potential and TTSW can be derived:

$$
\text { d } \Psi_{p d} / \mathbf{d} t=-(2.5 / 5.66)\left(k_{c b} \times E T_{o} / T T S W\right)
$$

that is very near the easy to recall expression:

$$
\text { d } \Psi_{p d} / \mathbf{d} t=-0.44 \times k_{c b} \times E T_{o} / T T S W
$$

As an example, let us choose $k_{c b}=0.5 ; E T_{o}=6 \mathrm{~mm}_{\text {day }}{ }^{-1} ; T T S W=150 \mathrm{~mm}$. The grapevine predawn water potential change in drought condition approaches -0.0088 MPa per day or $-0.06 \mathrm{MPa}$ per week.

During a long period without rain and supposing $k_{c b}$ constant over this period (which is the case when vegetation has attained its full development or is stabilized by trimming operations), the previous mathematical development can be integrated leading to Eq. 6 :

$$
\Psi_{p d}=-0.44 \times k_{c b} / T T S W \times\left(\Sigma E T_{o}\right)+\text { constant }
$$

The following units apply to the previous relationship: $\Psi_{p d}$ in $\mathrm{MPa}, T T S W$ in $\mathrm{mm}, E T_{o}$ in $\mathrm{mm} \cdot \mathrm{d}^{-1},\left(\Sigma E T_{o}\right)$ in $\mathrm{mm}$.

The next sections of the paper will describe experiments used to verify the proposed formalization. Validation will focus on testing relevance of Eq. 6 with experimental data-sets providing $\Psi_{p d}$ and $E T_{o}$ values. From Eq. 6, this validation will be performed considering the following relationship:

$$
\Psi_{p d}=\text { Slope } \mathrm{x}\left(\Sigma E T_{o}\right)+\text { constant }, \text { with Slope }=-0.44 \times k_{c b} / T T S W
$$

The resulting unit of Slope is MPa.mm ${ }^{-1}$.

A simple expression giving TTSW from Slope and $k_{c}$ can be obtained from Eq. 7:

$$
T T S W=-0.44 \times k_{c b} / \text { Slope }
$$

Validation will aim at checking the fitting of the linear model with classical statistics as well as verifying the relevance of the Slope values estimated over two fields, one planted with Shiraz and the other with Mourvedre. These two varieties may present different responses to water restriction. Shiraz with an optimistic behavior is more susceptible to water stress than other varieties (Schultz, 2003; Ojeda et al., 2005), Mourvedre for instance (Prieto et al., 2010).

\section{Materials and Methods}

Over the last 20 years, year 2003 and in a lesser extent 2005, were identified as the best summer periods to test the relevance of Eq. 8 in the south of France. Indeed, both these years, Languedoc experienced very dry conditions. Predawn leaf water potential data were collected in 2003 for one variety (Shiraz) and in 2005 for the other variety (Mourvedre) by Acevedo-Opazo et al. (2010) in vineyards of Pech Rouge (INRAGruissan, $43^{\circ} 08^{\prime} 47^{\prime}$ N, $03^{\circ} 07^{\prime} 19^{\prime \prime}$ E). The Shiraz vineyard of 1.2 ha was planted in 1990 (Fig. 1). The Mourvedre vineyard of 1.7 ha was also planted in 1990. Both are included in the la Clape terroir which is classified as designation of origin by the French authority. The northern limits of this terroir follow the lower course of the river Aude 
and the southern limits follow an ancient course of the same river. The corresponding geological terrain is Cretaceous limestone, mainly constituted of thick Orbitolina deposits (Lespinasse, 1982). Over time, this geological material has given rise to heterogeneity in the pedological material.

$\mathbf{a}$

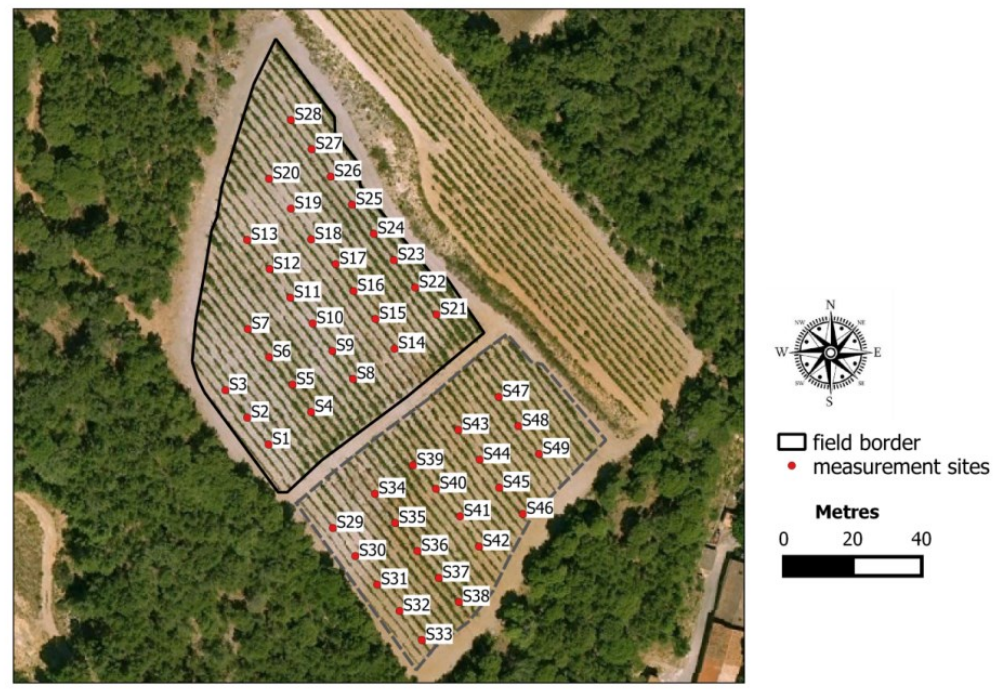

b

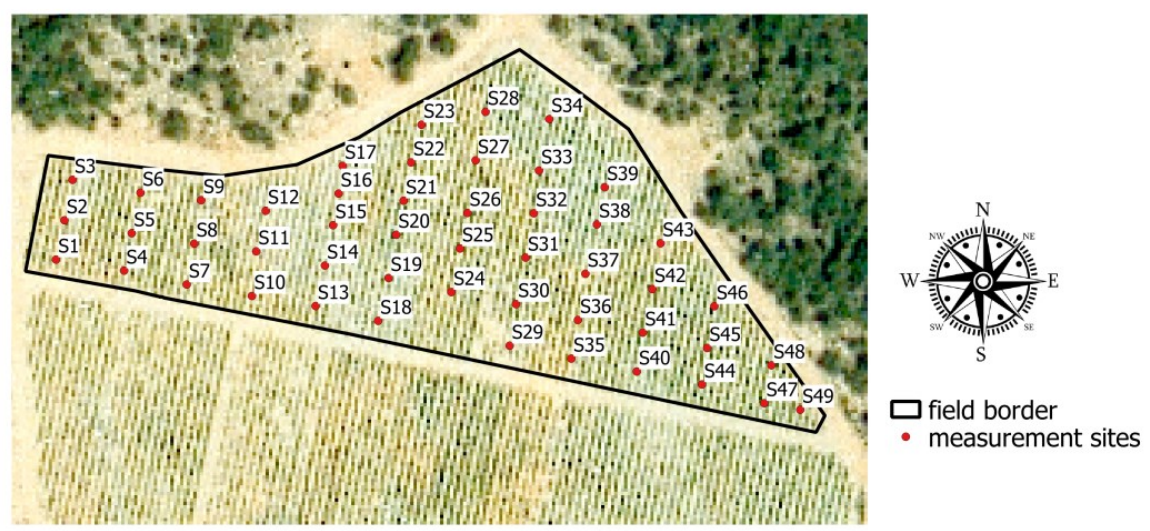

Figure 1. Map of Shiraz (a) and Mourvedre (b) fields and their 49 measurement sites.

In the two vineyards, the soil is predominantly classified Hyperskeletic calcaric leptosol (WRB, 2014) with 0.4-0.8 $\mathrm{m}$ depth and high stoniness (limestone pebbles). In some parts of the fields, the parent material can be cretaceous intercalations of marl and limestone. The depth is then $0.4-1.5 \mathrm{~m}$ and the corresponding zone is classified colluvic calcaric regosol (Coulouma et al., 2016). The spatial distribution of these two soil units is however difficult to address at the within-field scale. In a field located $100 \mathrm{~m}$ away from the Shiraz field, on the same pedo-geological context, Coulouma et al. (2010) described alternation of gravelly soil over Orbitolina-bearing marlstone and clayey 
gravelly soil over red clay (less than $1 \mathrm{~m}$ thick). Such variations, if present in the experimental fields, will influence the water stress experienced by vines.

In both vineyards, because of rocks (Fig. 2), installation of probes dedicated to soil water content or the soil water potential measurements was hardly possible. For the same reason, the vine rooting depth was impossible to estimate, even with direct observations.

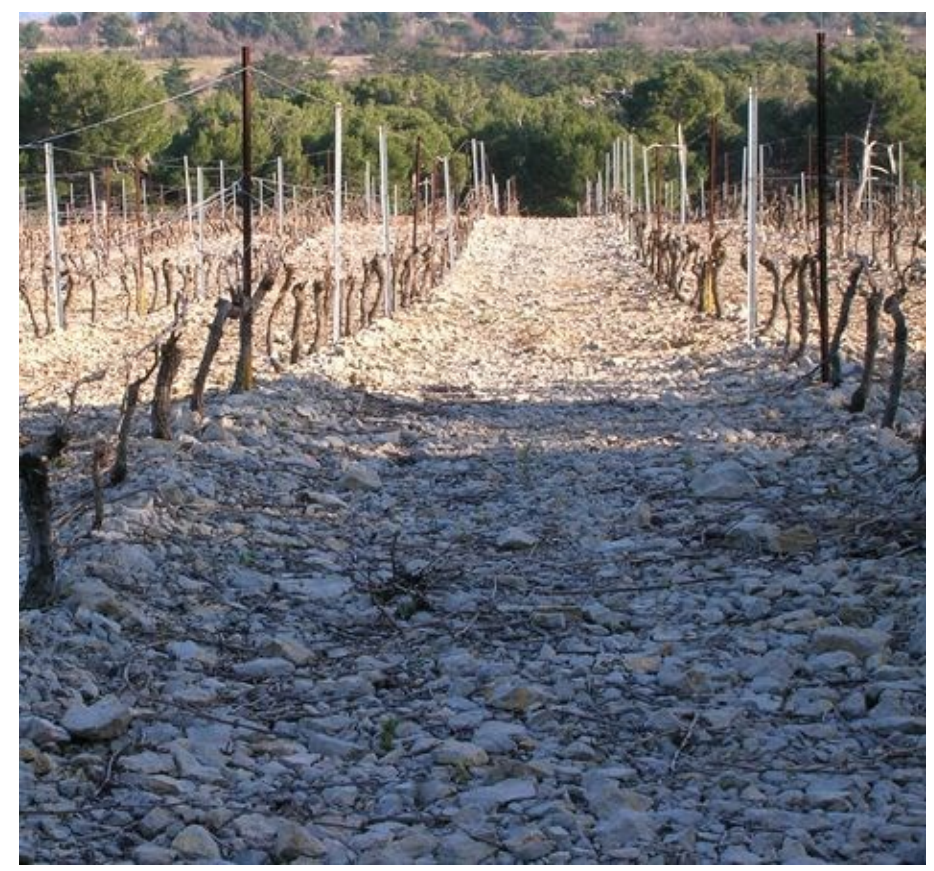

Figure 2. The rocky soil of la Clape vineyards

No irrigation system was used, first because this was the choice of the owner (Unité expérimentale de Pech Rouge), secondly because it would be costly to bring water to the distant Mourvedre field, thirdly because the yield objective of the la Clape appellation is low, around $40 \mathrm{hL} \cdot \mathrm{ha}^{-1}$.

Vines were trained in a vertical shoot positioning system with spacing of $1 \mathrm{~m}$ between vines and $2.5 \mathrm{~m}$ between rows.

Predawn leaf water potential measurements were carried out between 3 and 5 a.m. on vines located on 49 sites of the fields (Acevedo-Opazo et al., 2010). These sites were defined following a regular grid as presented in Fig. 1. Measurements were made with a pressure chamber (Scholander et al., 1965) at seven dates in 2003 and six dates in 2005. These measurements began two weeks (in 2003) or one week (in 2005) after full vegetation development was observed (beginning of June). The flowering and veraison stages were noted just after mid-May and mid-August, respectively. The pressure chamber was a Plant Water Status Console, Model 3000 (Soil moisture Equipment Corp., Santa Barbara, California). One date-site data corresponds to the average of three measurements on three representative vines at one site. In order to perform measurements over the 49 sites in a short period of time (between 3 and 5 a.m.), the following organization was used: Three technicians and researchers collected the leaves and brought them to a researcher (the same person for Shiraz and Mourvedre fields) in 
charge of measurements on the console. A laser Tachymeter (TPS 1001, Leica, Heerbrugg, Switzerland) was used for location of each of 49 sites (Acevedo-Opazo et al., 2010).

Climatic data were monitored by the Pech Rouge weather station located $100 \mathrm{~m}$ away from the Shiraz field (500 $\mathrm{m}$ away from the Mourvedre field). These climatic data were used to compute the reference evapotranspiration $\left(E T_{o}\right)$ according to Allen et al. (1998).

For each site, following Eq. 7, a linear regression of $\Psi_{p d}$ according to reference evapotranspiration was computed using the classical least square method. To this end, all the data were used in the Shiraz field when only four dates were used for the Mourvedre field. It was therefore possible to estimate the Slope parameter for each site. In the Shiraz field, a transect (AB) (Fig. 3) encompassing five sites was chosen to repre-

a

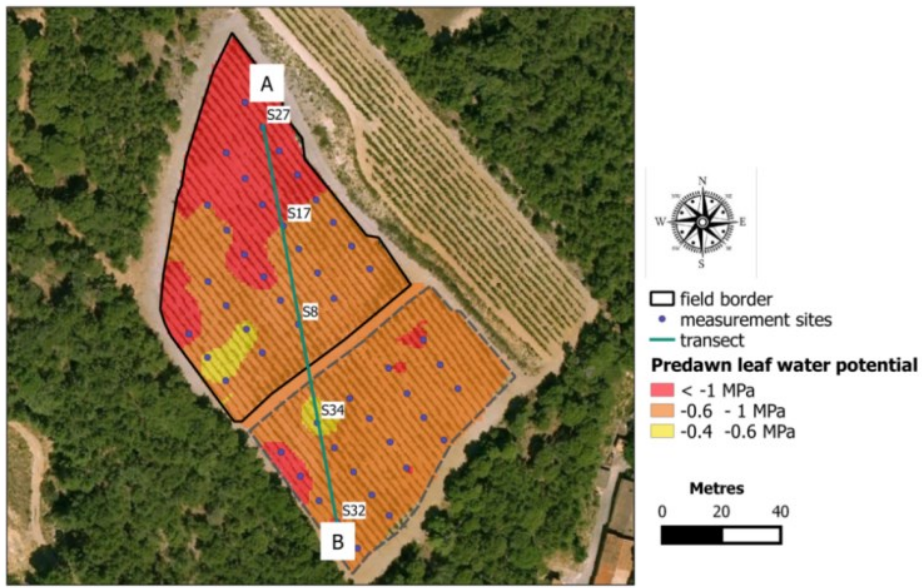

b
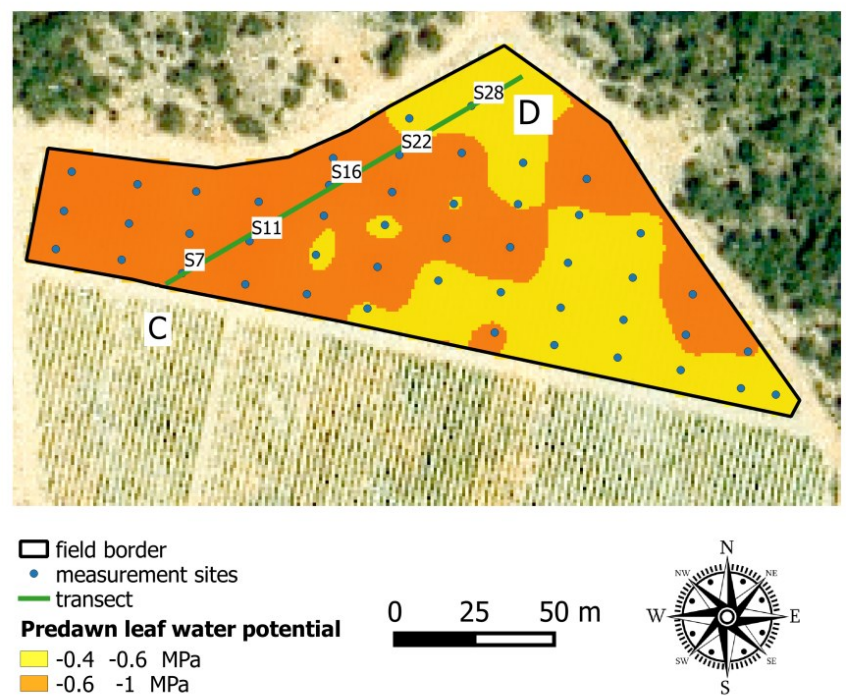

Figure 3. Map of predawn leaf water potential on August $12^{\text {th }} 2003$ (Shiraz, a) and August $5^{\text {th }} 2005$ (Mourvedre, b) from $\Psi_{p d}$ measurement on 49 sites. Each blue point represents one site. The transect (AB) was selected for detailed analysis of results for sites 27, 17, 8, 34, 32 in Shiraz. The transect (CD) included sites 7, 11, 16, 22, 28 in Mourvedre. 
sent the magnitude of soil dryness variation as shown on the map of $\Psi_{p d}$ on August $12^{\text {th }}$ 2003 (Fig. 3). Sites belonging to the AB transect were used to provide more insights on the results.

In the Mourvedre field, the transect (CD) (Fig. 3) was chosen for the same objective. For the five sites of each transect, the TTSW was calculated from Eq. 8 assuming a $k_{c b}$ value of 0.45 . This value was derived from measurements (height and width of vegetation, porosity) in a previous study with identical vine and soil management (Gaudin et al., 2014a). To understand the influence of $k_{c b}$ on TTSW evaluation, a sensitivity analysis was performed by taking into account a $15 \%$ variation around the $k_{c b}$ value of 0.45 chosen for the demonstration.

Data mapping was performed using QGIS (Quantum GIS Development, V1.8, Open Source Geospatial Foundation Project) by importing Easting and Northing and values for field variables ( $\Psi_{p d}$ and proposed slope). Data interpolation was performed using GeoFIS (V0.1, INRA/IRSTEA/Montpellier SupAgro, France). The interpolation method used in this study was based on simple kriging after the semi-variogram model was determined for each variable. The semi-variogram model was fitted manually on the experimental semi-variogram points with the interface of software GeoFIS which is specifically designed to this end. Once interpolated, classes of $\Psi_{p d}$ used by AcevedoOpazo et al. (2010) were applied to map data. Concerning the estimation of the Slope parameter, classes were defined according to data distribution in $25 \%$ quantiles. In this last case, four classes were therefore considered for $\Psi_{p d}$ : low (0-25\% quantile), lowmedium (25-50\% quantile), medium-high (50-75\% quantile) and high (75-100\% quantile).

\section{Results}

Sparse and very low precipitations were observed from June to November 2003 (Fig. 4).

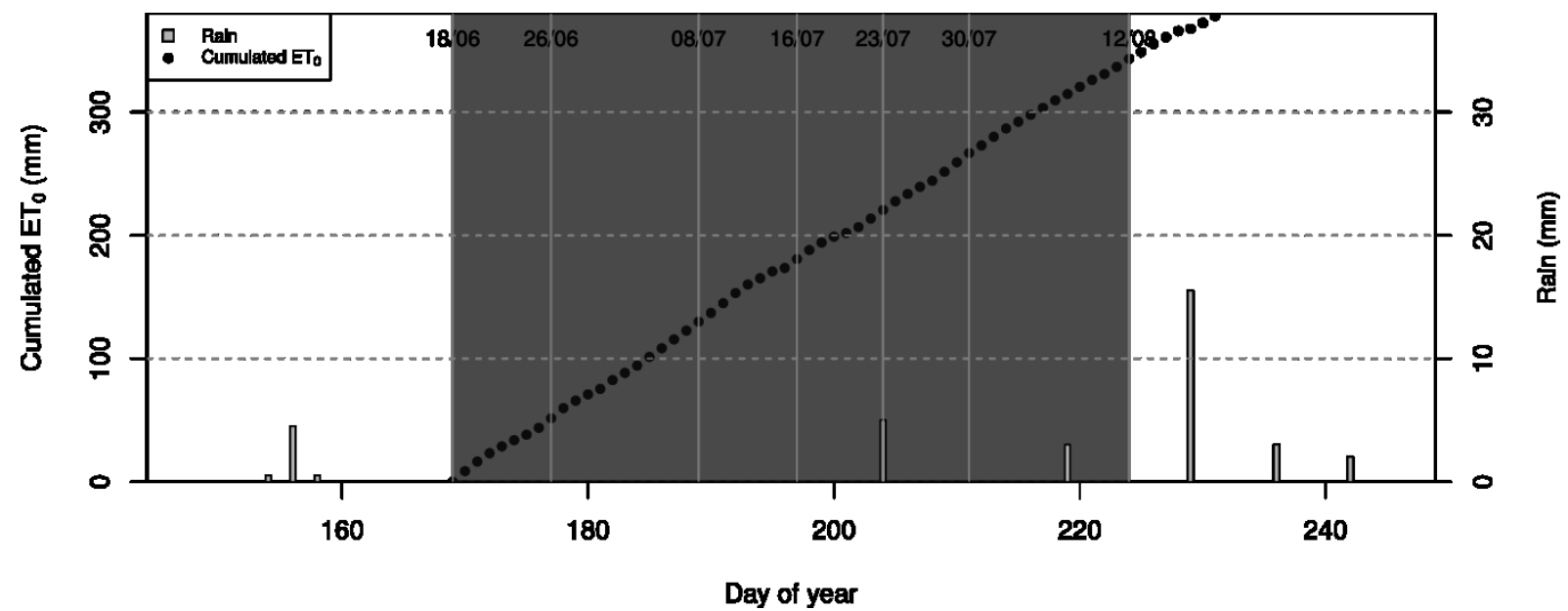

Figure 4 (first part). Rain (bars) and sum of reference evapotranspiration (points) versus time for Shiraz field in 2003. The dates for $\Psi_{p d}$ observation are indicated on the upper side of the graph. The time origin (starting point of grey zone) for cumulated $E T_{o}$ is taken at the first date of $\Psi_{p d}$ measurement after a long dry period. The test is performed on $\Psi_{p d}$ observations performed in the grey zone. 
During this period, the highest daily precipitation was $15.5 \mathrm{~mm}$ on August $17^{\text {th }}$. Between June 10 (eight days before the first date of $\Psi_{p d}$ measurements) and August 12 (last date), only two minor events of precipitation $(5 \mathrm{~mm}$ and $3 \mathrm{~mm}$ ) were recorded (Fig. 4). During the experiment, precipitations were therefore considered low enough to be neglected in the following analysis. These results highlighted the ideal climatic conditions of summer 2003 to perform our test.

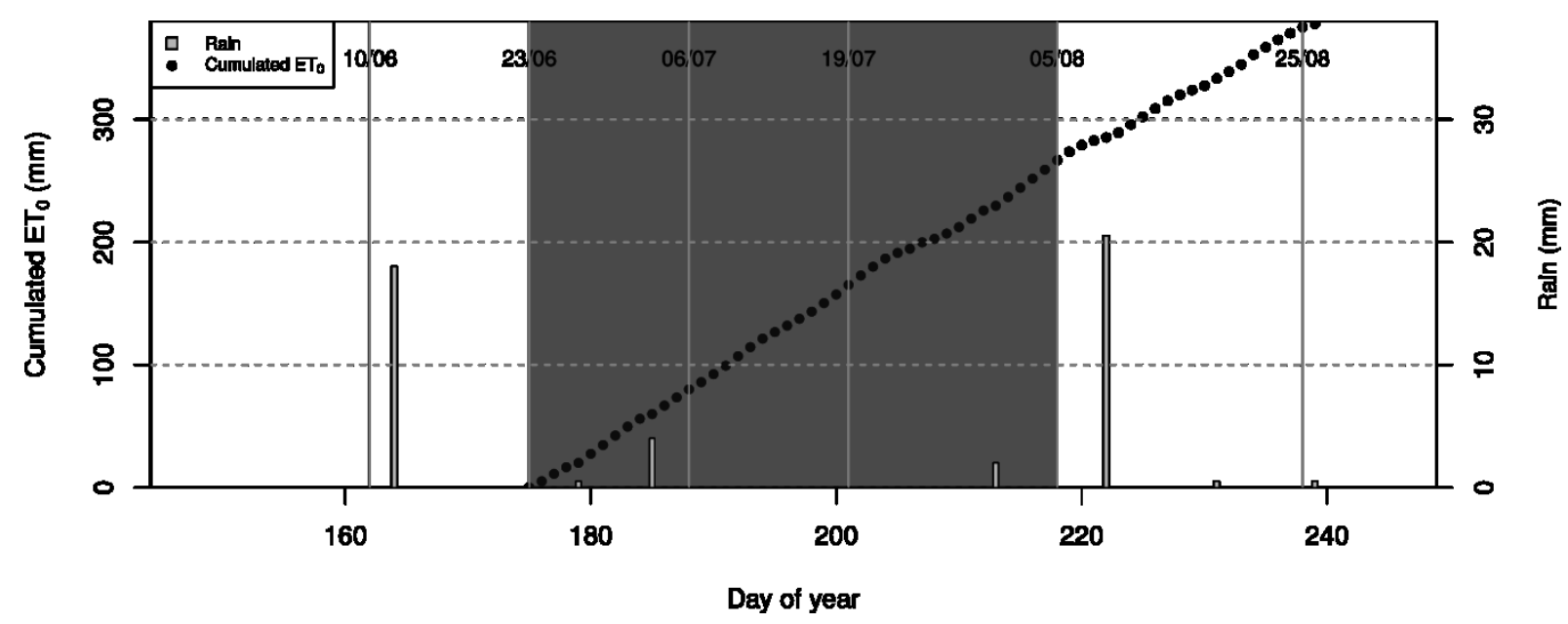

Figure 4 (second part). Rain (bars) and sum of reference evapotranspiration (points) versus time for Mourvedre field in 2005

In 2005, precipitations occurred on June $13^{\text {th }}(18 \mathrm{~mm})$ ten days before the second date of $\Psi_{p d}$ measurement (June $23^{\text {rd }}$ ). Two minor events $(4 \mathrm{~mm}$ and $2 \mathrm{~mm}$ ) were recorded before the fifth date of $\Psi_{p d}$ measurement (August $5^{\text {th }}$ ). A major rain event $(20.5 \mathrm{~mm})$ was recorded on August $10^{\text {th }}$, before the sixth date of $\Psi_{p d}$ measurement. Therefore, the dry soil condition can be considered valid only during a period of time encompassing four dates of $\Psi_{p d}$ measurement.

Regarding the regression model and Slope estimation, the fittings $\left(r^{2}\right)$ of the linear model (Eq. 7) estimating $\Psi_{p d}$ with cumulative $E T_{o}$ were high on most of the sites. Very strong adjustments $\left(r^{2}>0.9\right)$ were observed for 33 sites of the Shiraz field and for 42 sites of the Mourvedre field. Table 1 shows the statistics of $p$-value observed over the 49 sites of the fields. These statistics take into account the number of observations used in the adjustment ( 7 and 4 dates leading to 6 and 3 degrees of freedom, respectively for Shiraz and Mourvedre). In general fittings were better for Shiraz in 2003 than for Mourvedre in 2005. For all of the sites, a p-value $<0.05$ was observed showing the statistical significance of the regression fittings. 
Table 1. Distribution of the level of significance of the linear relationship between $\Psi_{p d}$ and cumulated $E T_{o}$ for the two series of observations

\begin{tabular}{ccc} 
Level of significance & $\begin{array}{c}\text { Number of sites } \\
\text { Shiraz 2003 }\end{array}$ & $\begin{array}{c}\text { Number of sites } \\
\text { Mourvedre 2005 }\end{array}$ \\
\hline $0.01<\mathrm{P}<$ or $=0.05$ & 2 & 8 \\
$0.001<\mathrm{P}<$ or $=0.01$ & 8 & 36 \\
$\mathrm{P}<$ or $=0.001$ & 39 & 5
\end{tabular}

The estimated Slope values range from -0.0039 (sites 18 and 20) to $-0.0007 \mathrm{MPa}^{-\mathrm{mm}^{-1}}$ (site 34) in Shiraz field. For the Mourvedre field, they range from -0.0036 (sites 12 and 31) to $-0.0013 \mathrm{MPa} . \mathrm{mm}^{-1}$ (site 20). Regarding the AB transect (Fig. 5), estimated Slope values were -0.0027 (site 27), -0.0024 (site 17), -0.0017 (site 8), -0.0007 (site 34) and $0.0021 \mathrm{MPa} \cdot \mathrm{mm}^{-1}$ (site 32).
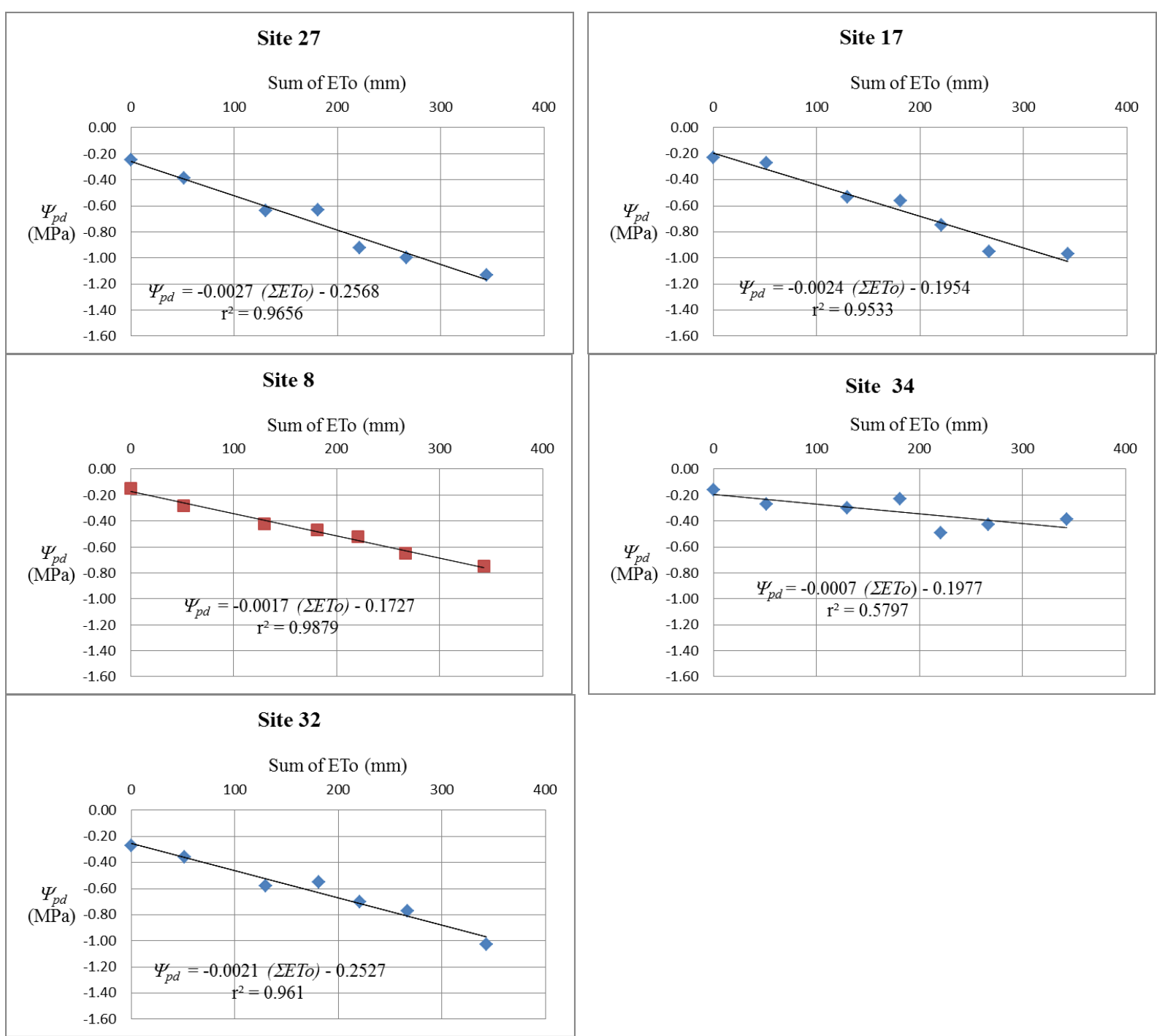

Figure 5. Evolution of $\Psi_{p d}$ versus cumulated $E T_{o}$ since June $18^{\text {th }} 2003$ for the five sites of $(\mathrm{AB})$ transect in Shiraz field. 
For CD transect (Fig. 6), estimated Slope values were -0.0024 (site 7), -0.0034 (site 11),

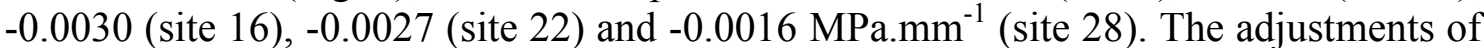
the regression model for sites of $\mathrm{AB}$ and $\mathrm{CD}$ transects are all significant. $\mathrm{r}^{2}$ values ranged from 0.58 (site 34) to 0.99 (site 8) in the Shiraz field and from 0.92 (site 7) to 0.98 (site 11) in the Mourvedre field showing the relevance of the model to explain $\Psi_{p d}$ measurements with $E T_{o}$ data.
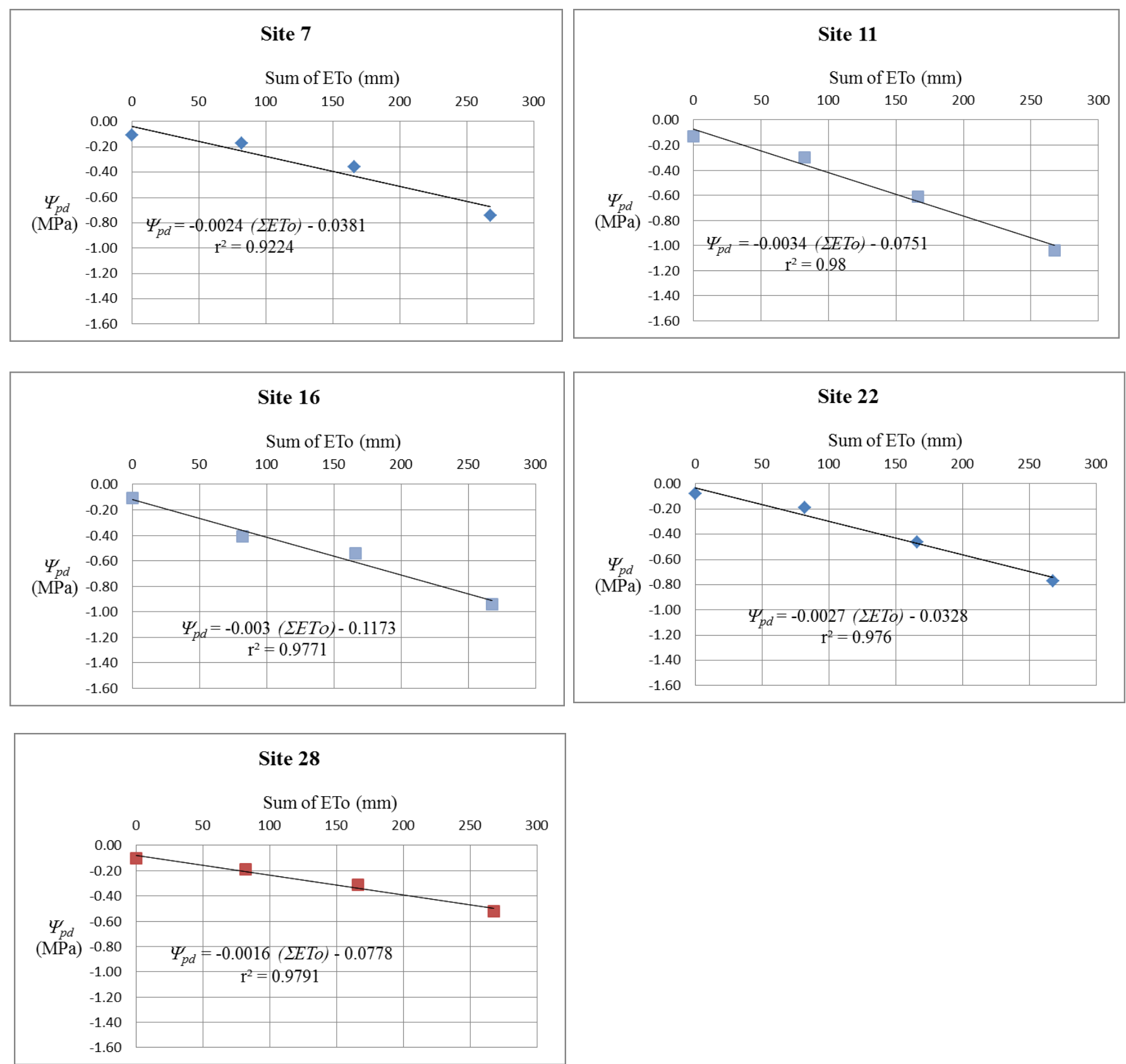

Figure 6. Evolution of $\Psi_{p d}$ versus cumulated $E T_{o}$ since June $23^{\text {rd }} 2005$ for five sites of (CD) transect in Mourvedre field. 
The AB transect (Shiraz field) presents lower Slope values from the northern part of the field where vines experienced the driest conditions in August 2003 (Fig. 3). Higher Slope values are observed in the middle and southwestern part of this field. An overview of the spatial organization of Slope values in this field is presented on an interpolated map (Fig. 7). The map of Slope values may be compared to the $\Psi_{p d}$ map on August $12^{\text {th }} 2003$ (Fig. 3). Both maps present the same spatial patterns, particularly the red zones corresponding either to low Slope values or to high water stress. Comparing Fig. 3 to Fig. 7 highlights a high correspondence between both maps.
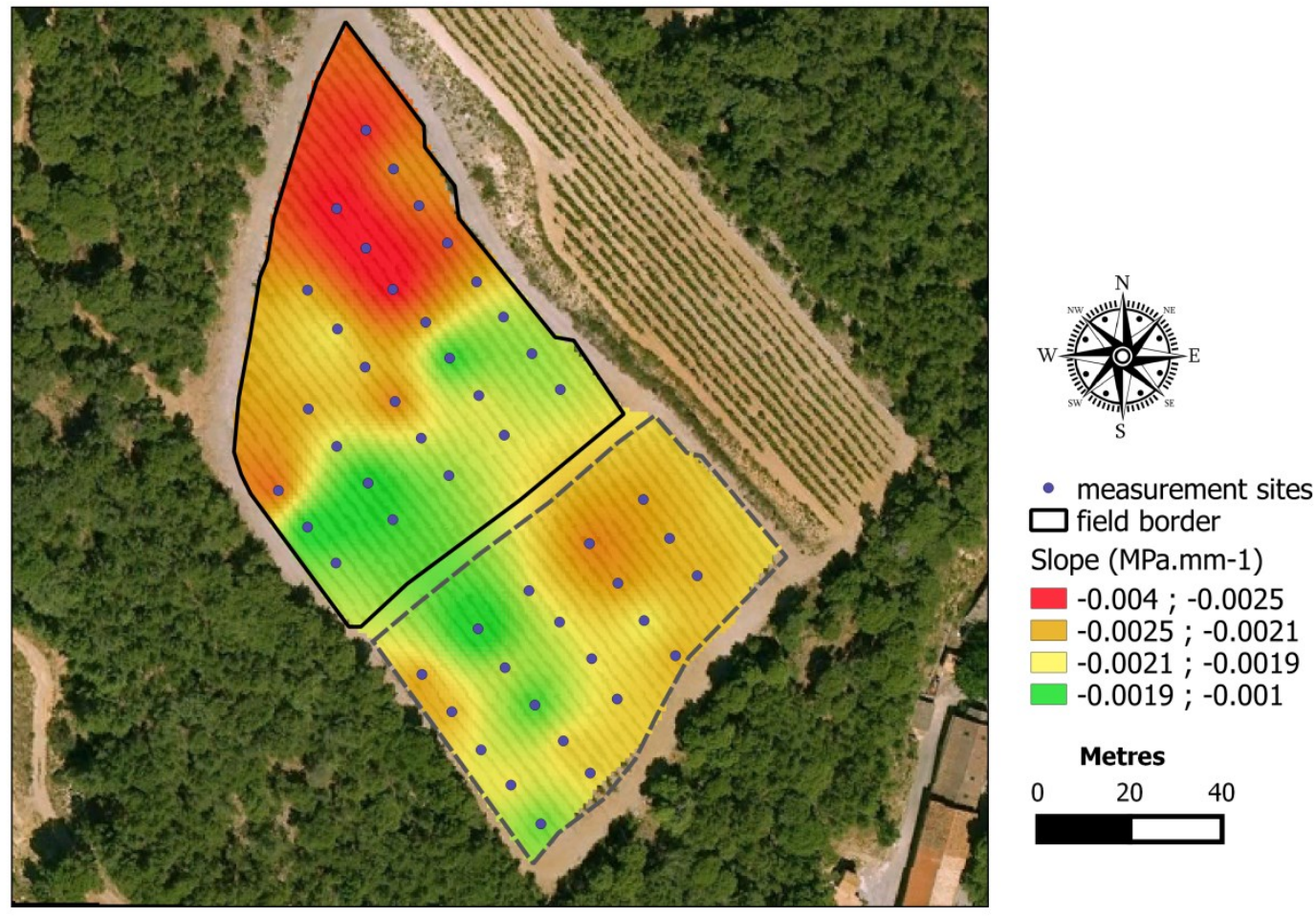

Slope (MPa.mm-1)

$-0.004 ;-0.0025$

$-0.0025 ;-0.0021$

$-0.0021 ;-0.0019$

$-0.0019 ;-0.001$

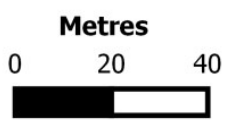

Figure 7. Map of the Shiraz field showing the slope of the relationship between $\Psi_{p d}$ and cumulated $E T_{o}$. Unit of Slope: MPa $\mathrm{mm}^{-1}$.

The sensitivity analysis enables to precise the magnitude of TTSW variation behind the spatial variation of Slope. For (CD), calculation of TTSW leads to values below $100 \mathrm{~mm}$ in four sites, between 105 and $142 \mathrm{~mm}$ for the fifth site (Table 3). For (AB), one site presents a very high TTSW (Table 2). The range of variation of estimated TTSW values is quite similar for two sites of (AB) and four sites of (CD). If we apply a simple rule of non-overlapping values of TTSW for discrimination between sites of a same transect (Table 2), it appears that site 34 presents a very different TTSW from other sites of (AB). Site 8 has a higher TTSW compared to sites 27 and 17 but site 8 cannot be discriminated from site 32 . Using the same criterion for (CD), site 7 is discriminated from site 11 but these two sites cannot be discriminated from sites 16 and 22 (Table 3). 
Table 2. Estimation of TTSW range from $k_{c b}$ variation of $15 \%$ around a common value of 0.45 , for the five sites of $(\mathrm{AB})$ transect in Shiraz field

\begin{tabular}{|c|c|c|c|c|c|c|}
\hline \multicolumn{2}{|c|}{ Site number } & 27 & 17 & 8 & 34 & 32 \\
\hline \multicolumn{2}{|c|}{ Slope $\left(\mathrm{MPa} \cdot \mathrm{mm}^{-1}\right)$} & -0.0027 & -0.0024 & -0.0017 & -0.0007 & -0.0021 \\
\hline $\begin{array}{l}T T S W \text { values (in } \\
\text { mm) considering }\end{array}$ & $\begin{array}{l}k_{c b} \times(1- \\
15 \%)=0.38\end{array}$ & 62 & 70 & 99 & 240 & 80 \\
\hline a variation of & $k_{c b}=0.45$ & 73 & 82 & 116 & 283 & 94 \\
\hline $\begin{array}{c}+/ 15 \% \text { around } \\
k_{c b}=0.45\end{array}$ & $\begin{array}{l}k_{c b} \times(1+15 \%) \\
=0.52\end{array}$ & 84 & 95 & 134 & 325 & 108 \\
\hline $\begin{array}{l}\text { Cases of overlapp } \\
\text { (same letter) }\end{array}$ & g values of $T T S W$ & $\mathrm{a}$ & $\mathrm{a}$ & $\mathrm{b}$ & $\mathrm{c}$ & $\mathrm{ab}$ \\
\hline
\end{tabular}

Table 3. Estimation of TTSW range from $k_{c b}$ variation of $15 \%$ around a common value of 0.45 , for the five sites of (CD) transect in Mourvedre field

\begin{tabular}{|c|c|c|c|c|c|c|}
\hline \multicolumn{2}{|c|}{ Site number } & 7 & 11 & 16 & 22 & 28 \\
\hline \multicolumn{2}{|c|}{ Slope $\left(\mathrm{MPa} \cdot \mathrm{mm}^{-1}\right)$} & -0.0024 & -0.0034 & -0.0030 & -0.0027 & -0.0016 \\
\hline $\begin{array}{l}T T S W \text { values (in mm) } \\
\text { considering a }\end{array}$ & $\begin{array}{l}k_{c b} \times(1-15 \%) \\
=0.38\end{array}$ & 70 & 50 & 56 & 62 & 105 \\
\hline variation of $+/-15 \%$ & $k_{c b}=0.45$ & 82 & 58 & 66 & 73 & 124 \\
\hline around $k_{c b}=0.45$ & $\begin{array}{l}k_{c b} \times(1+15 \%) \\
=0.52\end{array}$ & 95 & 67 & 76 & 84 & 142 \\
\hline $\begin{array}{l}\text { Cases of overlapping } \\
\text { (same letter) }\end{array}$ & lues of $T T S W$ & $\mathrm{~b}$ & $\mathrm{a}$ & $a b$ & $a b$ & c \\
\hline
\end{tabular}

\section{Discussions}

The whole data-set shows that the relationship (7) was verified either in 2003 or in 2005 (Table 1). Comparison of $\mathrm{AB}$ and $\mathrm{CD}$ transects shows that the water stress was extreme in the Shiraz field where 3 sites present $\Psi_{p d}$ values less than -1 MPa while only 1 site reaches this level of water stress on the Mourvedre field. However, $\Psi_{p d}$ less than -0.60 $\mathrm{MPa}$ was observed in all sites of the two transects, except one. The validity of the relationship (7) is consequently associated with high levels of water stress. It confirms the observations of Taylor et al. (2010) showing the preponderance of soil condition over varietal factors for the occurrence of differences in $\Psi_{p d}$.

In the Shiraz field, site 34 presents a particular behavior with the highest Slope value and least significant adjustment (Fig. 5). The small area of high $\Psi_{p d}$ (Fig. 3) surrounding this site can be interpreted as special soil conditions affecting the vines. Soil heterogeneity at a very local scale should be reflected in the sample of leaves and then in $\Psi_{p d}$ observations. The highest slope corresponds to the lowest ratio of $k_{c b}$ to TTSW so that the suspected heterogeneity concern TTSW at this very local scale. TTSW of site 34 attains a peak value around $280 \mathrm{~mm}$ (Table 2). Coulouma et al. (2010) have pointed out 
the occurrence of local alternation of calcareous rocks and clay in the pedological context of la Clape. They identify three classes of soil availability, a first one of low water availability for gravelly soil on marlstone, an intermediate one for clayey gravelly soil over red clay or loamy colluvial deposit and a third one of high water availability. Site 34 may fall in this latter class: clay (or loam) material with favorable water conditions for the vines.

Comparing the Slope values obtained from both fields, they present the same range except for the high value of site 34 (Shiraz). For both fields the distribution of the Slope parameter shows that at least $80 \%$ of the values are between -0.0034 to -0.0016 MPa.mm ${ }^{-1}$ (data not shown). This is a significant magnitude which may be due to variation in soil texture and depth.

However because of the contrasted levels of water stress, observed for Shiraz field in June (Acevedo-Opazo et al., 2010), vegetative development of vines (notably for those growing on sites of low TTSW) could have been differently impacted. Thus the basal crop coefficient may vary within the field. Unfortunately, estimation of within field variation in $k_{c b}$ is not available since no measurement of the canopy (height and width of full vegetation and porosity), aiming at estimate $k_{c b}$ (Pieri and Gaudillère, 2005), were performed during the experiment. As a result, variation in Slope values cannot be exclusively attributed to TTSW variation although this latter is assumed to have the highest effect. On the other hand, the topping and trimming operations tend to homogenize canopy size (and the resulting $k_{c b}$ coefficient) and thus limit $k_{c b}$ variability over the field.

Focusing on the Shiraz field, some significant but limited variation of $k_{c b}$ may be assumed, mainly because the water stress was effective only in June, two months after bud-break. A decrease of 0.1 in $k_{c b}$ value relatively to the winegrower objective, which was around a $k_{c b}$ of 0.45 , is thus possible for some sites of the field. In order to take this variability into account, variations of $k_{c b}$ values from 0.35 to 0.5 were considered (Fig. 8 ). With these $k_{c b}$ values, for each site with its slope value, it is then possible to proceed to $T T S W$ calculations according to Eq. 8 (Fig. 8).

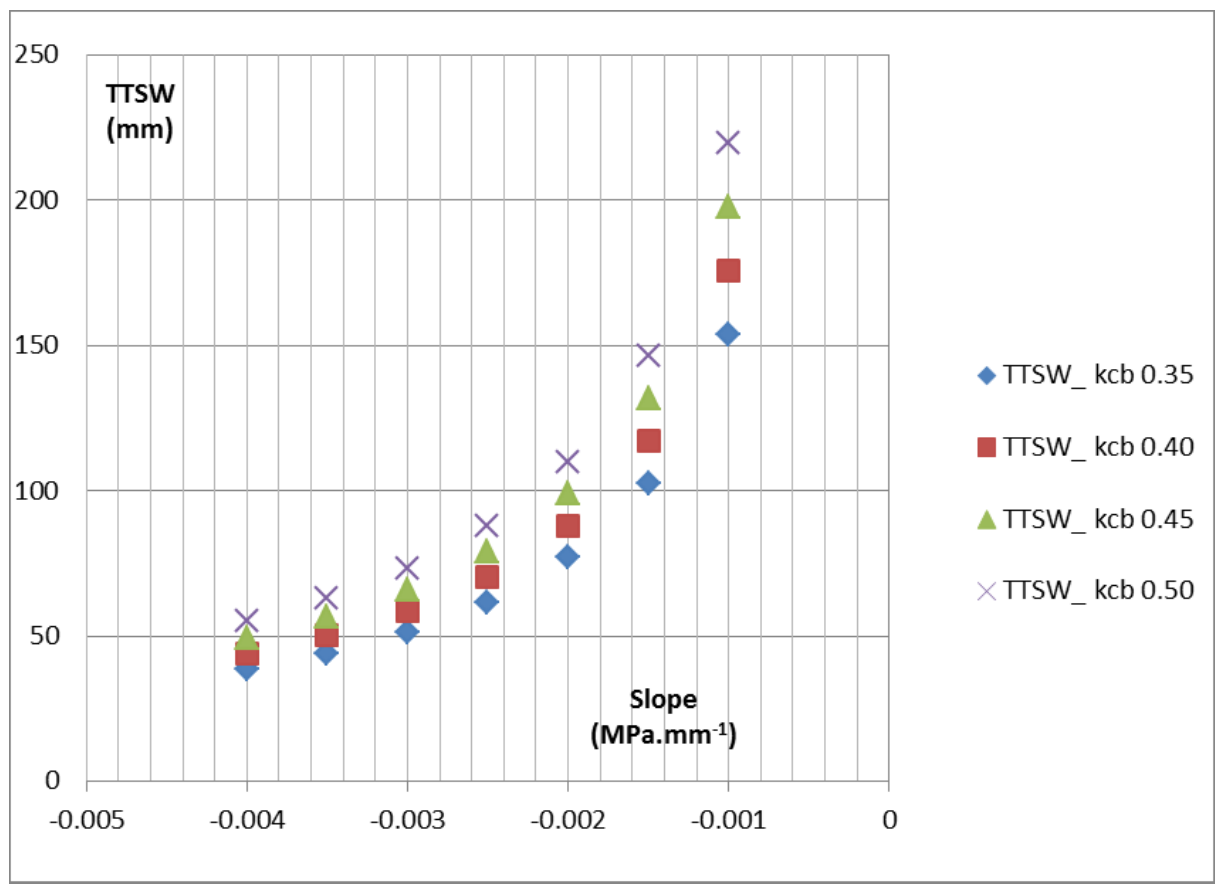

Figure 8. Determination of TTSW from various slope and basal crop coefficient values. 
Still focusing only on results observed on the Shiraz field, this analysis is as follows. TTSW would range from 65 to $110 \mathrm{~mm}$ when Slope values are between -0.0025 and $0.0019 \mathrm{MPa}_{\mathrm{mm}}{ }^{-1}$ (Fig. 8); this corresponds to the yellow and orange zones of the Slope map (Fig. 7). This TTSW range corresponds to depth and stoniness of calcaric leptosol described by Coulouma et al. (2010). Slopes below $-0.0025 \mathrm{MPa}^{\mathrm{mm}} \mathrm{m}^{-1}$ are observed in the northern part of the field and correspond to small TTSW $(50-60 \mathrm{~mm})$ ("hyperskeletic" attributes). Slopes higher than $-0.0019 \mathrm{MPa} . \mathrm{mm}^{-1}$ are observed in the southern part of the field ("colluvic calcaric" attributes); one value higher than -0.001 MPa.mm ${ }^{-1}$ (site 34 on transect AB) corresponds to the peak value of TTSW. A similar reasoning, leading to very similar results was performed for the Mourvedre field (data not shown).

Canopy size measurement should have eased our analysis and enabled to highlight the respective incidence of $k_{c b}$ and TTSW in Slope variation. Nevertheless, the data of leaf predawn water potential allow the inversion approach as developed in the first part of the paper to validate: linear relationship between $\Psi_{p d}$ and cumulated reference evapotranspiration, Slope value in relation with local soil. Such historical data concerning leaf predawn water potential are relatively common in the Mediterranean context as $\Psi_{p d}$ is used by extension services to provide with growers information about vine water stress. In the future, it will be important to record the canopy size to limit the uncertainty on TTSW estimate.

The inversion problem has been applied at a within field scale. This scale is rarely considered by the wine industry. It is however well known that the total available water varies in orchards (Grashey-Jensen, 2010) and that this variation has to be taken into account for irrigation management (Grashey-Jensen, 2014). The spatial variation observed in our study is significant. If canopy measurements had been carried out, the method should have permitted a very precise mapping of TTSW in a situation where the classical methods of soil water measurements are hardly possible.

At a larger scale, it should be possible to monitor the vegetation by satellite-imaging and study the relation of $k_{c b}$ with the NDVI (normalized difference vegetation index). Campos et al. (2016) have performed this operation in various vineyards together with evapotranspiration measurements. These data were assimilated in a water balance model in order to estimate the water soil reservoir (one value per vineyard). The method applies for rain-fed as well as irrigated vineyards provided with the instruments for evapotranspiration measurement.

Working (as we have in this paper) only on long dry periods simplifies the way to inversion. Working on leaf predawn water potential measurements and using the relation of Lebon et al. (2003) enable to assess the soil water reservoir in fields where soil water content (or soil water potential) measurements are impossible. This is the case of numerous qualitative vineyards of the Mediterranean region.

From a practical point of view, the relationship (7) may be used to forecast $\Psi_{p d}$ evolution for irrigation management purposes. During a long drought period, the time at which $\Psi_{p d}$ will reach a fixed threshold can be predicted from $\Psi_{p d}$ measurement at two or three dates. This threshold can be the limit of water stress acceptable for the vine (Ojeda, 2007; Gaudin and Gary, 2012; Gaudin et al., 2014a). Irrigation should be triggered at this time.

Another application should be to isolate, in a homogeneous field zone (same TTSW), a reference site from rain influence (i.e. by covering the soil just before rain events), and 
perform successive measurements of $\Psi_{p d}$ in this site. Resulting $\Psi_{p d}$ evolution with $E T_{o}$ calculated from data provided by a local weather station should lead to the estimation of the $k_{c b}$ to TTSW ratio. This empirical approach would make it possible to use this relevant information for an active water management in dry years. When a long dry period prevails, predawn water potential could be foreseen from a single point of measurement and previous acquisition of the $k_{c b}$ to TTSW ratio. If the level of stress reaches the threshold selected by the vine-grower, it should be time to trigger irrigation. Within large fields with high variability in soil depth or texture for example, different irrigation could result from different $k_{c b}$ to $T T S W$ ratio.

Apart from irrigation management purposes, the present work shows that it is possible to obtain soil information from historical data of predawn leaf water potential.

\section{Conclusion}

This work shows that under certain conditions, encountered in dry summers, the equations of classical water balance models can be simplified. Assuming no capillary rise (from a water-table or a deep wet layer of the soil) and no evaporation from the bare soil surface, a relationship linking the time derivative of $\Psi_{p d}$ with aerial $\left(k_{c b}\right)$ and soil $(T T S W)$ parameters can be established. This relationship was tested with databases collected in two vineyards during the dry summers of 2003 and 2005. The relationship was proven to be valid for the 49 sites of the fields which encompass a wide range of water stress intensities and two grape varieties, Shiraz and Mourvedre.

This work also shows that the statistical adjustment of this relationship on measurements of $\Psi_{p d}$ performed during dry summers provides an estimate of the ratio of $k_{c b}$ to TTSW. Its variation at the field scale was highlighted; for a full understanding of this variability, canopy measurements for $k_{c b}$ calculation should be performed. It would show further evidence of the importance of TTSW as a main source of $\Psi_{p d}$ variation in periods of drought.

\section{Acknowledgements}

We thank Hernan Ojeda and Nicolas Saurin (INRA Gruissan) for sharing data. We thank Christian Gary (INRA Montpellier) for reading the manuscript.

\section{References}

Acevedo-Opazo, C., Tisseyre, B., Ojeda, H., Guillaume, S., 2010. Spatial extrapolation of the vine (Vitis vinifera L.) water status: A first step towards a spatial prediction model. Irrigation Science 28, 143-155.

Allen, R.G., Pereira, L.S., Raes, D., Smith, M., 1998. Crop evapotranspiration. Guidelines for computing crop water requirements. Irrigation and drainage paper 56, FAO, Roma.

Campos, I., Balbontin, C., Gonzalez-Piqueras, J., Gonzalez-Dugo, M.P., Neale, C.M.U., Calera, A., 2016. Combining a water balance model with evapotranspiration measurements to estimate total available soil water in irrigated and rainfed vineyards. Agricultural Water Management 165, 141-152. 
Celette, F., Gaudin, R., Gary, C., 2008. Spatial and temporal changes to the water regime of a Mediterranean vineyard due to the adoption of cover cropping. European Journal of Agronomy 29, 153-162.

Celette, F., Ripoche, A., Gary, C., 2010. WaLIS- A simple model to simulate water partitioning in a crop association: The example of an intercropped vineyard. Agricultural Water Management 97, 1749-1759.

Coulouma, G., Caner, L., Loonstra, E., Lagacherie, P., 2016. Analysing the proximal gamma radiometry in contrasting Mediterranean landscapes: Towards a regional prediction of clay content. Geoderma 266, 127-135.

Coulouma, G., Tisseyre, B., Lagacherie, P., 2010. Is a systematic two-dimensional EMI soil survey always relevant for vineyard production management? A test of two pedologically contrasting Mediterranean vineyards. In: Viscarra Rossel, R.A., McBratney, A., Minasny, B. (Eds), Proximal Soil Sensing. Progress in Soil Science Series, Springer, New York, pp. 283-295.

Deloire, A., Ojeda, H., Zebic, O., Bernard, N., Hunter, J.J., Carbonneau, A., 2005. Influence de l'état hydrique de la vigne sur le style de vin. Le Progrès Agricole et Vinicole 21, 455-462.

Fandino, M., Cancela, J.J., Rey, B.J., Martinez, E.M., Rosa, R.G., Pereira, L.S., 2012. Using the dual-Kc approach to model evapotranspiration of Albarino vineyards (Vitis vinifera L. cv. Albarino) with consideration of active ground cover. Agricultural Water Management 112, 75-87.

Gaudin, R., Celette, F., Gary, C., 2010. Contribution of runoff to incomplete off season soil water refilling in a Mediterranean vineyard. Agricultural Water Management 97, 1534-1540.

Gaudin, R., Gary, C., 2012. Model-based evaluation of irrigation needs in Mediterranean vineyards. Irrigation Science 30, 449-459.

Gaudin, R., Gary, C., Wery, J., Coulon, V., Cazes, E., 2014a. Monitoring of irrigation in a Mediterranean vineyard: Water balance simulation versus pressure chamber measurement. ActaHort (ISHS) 1038, 295-302.

Gaudin, R., Kansou, K., Payan, J.C., Pellegrino, A., Gary, C., 2014b. A water stress index based on water balance modelling for discrimination of grapevine quality and yield. Journal International des Sciences de la Vigne et du Vin 48, 1-9.

Grashey-Jensen, S., 2010. Pedohydrological case study for two apple-growing locations in South Tyrol (Italy). Agricultural Water Management 98, 234-240.

Grashey-Jensen, S., 2014. Optimizing irrigation efficiency through the consideration of soil hydrological properties -Examples and simulation approaches. Erdkunde 68, 33-48.

Gruber, B.R., Schultz, H.R., 2005. Coupling of plant to soil water status at different vineyards sites. ActaHort (ISHS) 689, 381-390. 
Guix-Hebrard, N., Voltz, M., Trambouze, W., Garnier, F., Gaudillère, J.P., Lagacherie, P., 2007. Influence of watertable depths on the variation of the grapevine water status at the landscape scale. European Journal of Agronomy 27, 187-196.

Hofmann, M., Lux, R., Schultz, H.R., 2014. Constructing a framework for risk analyses of climate change effects on the water budget of differently sloped vineyards with a numeric simulation using the Monte Carlo method coupled to a water balance model. Frontiers in Plant Science 5, 645.

Koundouras, S., Marinos, V., Gkoulioti, A., Kotseridis, Y., Van Leeuwen, C., 2006. Influence of vineyard location and vine water status on fruit maturation of non-irrigated cv. Agiorgitiko (Vitis vinifera L.): effects on wine phenolic and aroma components. J. Agr. Food Chem. 54, 5077-5086.

Lebon, E., Dumas, V., Pieri, P., Schultz, H.R., 2003. Modelling the seasonal dynamics of the soil water balance of vineyards. Functional Plant Biology 30, 679-710.

Lespinasse, P., 1982. Notice explicative de la feuille géologique Narbonne 1/50 000. BRGM, Orléans.

Ojeda, H., 2007. Irrigation qualitative de précision de la vigne. Le Progrès Agricole et Viticole 124, 133-141.

Ojeda, H., Deloire, A., Carbonneau, A., 2001. Influence of water deficits on grape berry growth. Vitis 40, 141-145.

Ojeda, H., Lebon, E., Deis, L., Vita, F., Carbonneau, A., 2005. Stomatal regulation of Mediterranean grapevine cultivars in drought situations of the southern of France. In: Schultz, H. (Ed), Proc XIVth Int Conf GESCO, Geisenheim (Germany), 23-27 August 2005, pp. 581-587.

Pellegrino, A., Gozé, E., Lebon, E., Wery, J., 2006. A model-based diagnosis tool to evaluate the water stress experienced by grapevine in field sites. European Journal of Agronomy 25, 49-59.

Pellegrino, A., Lebon, E., Simonneau, T., Wery, J., 2005. Towards a simple indicator of water stress in grapevine (Vitis vinifera L.) based on the differential sensitivities of vegetative growth components. Australian Journal of Grape and Wine Research 11, 306-315.

Pellegrino, A., Lebon, E., Voltz, M., Wery, J., 2004. Relationships between plant and soil water status in vine (Vitis vinifera L.). Plant and Soil 266, 129-142.

Piéri, P., Gaudillère, J.P., 2005. Vines water stress derived from a water balance model - sensitivity to soil and training system parameters. In: Schultz, H. (Ed), Proc XIVth Int Conf GESCO, Geisenheim (Germany), 23-27 August 2005, pp. 457-463. 
Prieto, J.A., Lebon, E., Ojeda, H., 2010. Stomatal behavior of different grapevine cultivars in response to soil water status and air water vapor pressure deficit. Journal International des Sciences de la Vigne et du Vin 44, 9-20.

Riou, C., Valancogne, C., Pieri, P., 1989. Un modèle simple d'interception du rayonnement solaire par la vigne - vérification expérimentale. Agronomie 9, 441-450.

Scholander, P.F., Hammel, H.T., Bradstreet, E.D., Hemmingsen, E.A., 1965. Sap pressure in vascular plants. Science 148, 339-346.

Schultz, H.R., 1996. Water relations and photosynthetic responses of two grapevine cultivars of different geographical origin during water stress. Acta Horticulturae 427, 251-266.

Schultz, H.R., 2003. Differences in hydraulic architecture account for near-isohydric and anisohydric behaviour of two field-grown Vitis vinifera L. cultivars during drought. Plant Cell Environ. 26, 1393-1405.

Sinclair, R., Ludlow, M.M., 1986. Influence of soil water supply on the plant water regime of four tropical grain legumes. Australian Journal of Plant Physiology 13, 329341.

Taylor, J.A., Acevedo-Opazo, C., Ojeda, H., Tisseyre, B., 2010. Identification and significance of sources of spatial variation in grapevine water status. Australian Journal of Grape and Wine Research 16, 218-226.

Trambouze, W., Voltz, M., 2001. Measurement and modelling of the transpiration of a Mediterranean vineyard. Agricultural Forest Meteorology 107, 153-166.

Van Leeuwen, C., Friant, P., Choné, X., Tregoat, O., Koundouras, S., Dubourdieu, D., 2004. Influence of climate, soil, and cultivar on terroir. Am. J. Enol. Viticult. 55, 207217.

Van Leeuwen, C., Tregoat, O., Choné, X., Bois, B., Pernet, D., Gaudillère, J.P., 2009. Vine water status is a key factor in grape ripening and vintage quality for red Bordeaux wine. How can it be assessed for vineyard management purpose? Journal International des Sciences de la Vigne et du Vin 43, 121-134.

WRB, World Reference Base for Soil Resources, 2014. International soil classification system for naming soils and creating legends for soil maps. World Soil Resources Report N 106. FAO, Rome. 